\title{
Formação de Professores DE Sociologia: uM Estudo À LuZ DA TeOria Histórico-Cultural
}

\author{
Maria Valéria Barbosa ${ }^{1}$ \\ Sueli Guadelupe de Lima Mendonça²
}

\begin{abstract}
ReSUMO
0 objetivo deste artigo é fazer uma reflexão da trajetória do curso de Ciências Sociais da Faculdade de Filosofia e Ciências, Unesp/Marília, sob a perspectiva da teoria históricocultural, e destacar as contribuições mais relevantes à formação do professor de Sociologia, no contexto da implantação da obrigatoriedade da Sociologia no ensino médio, em nível nacional, visando à formação de um profissional comprometido com a educação pública de qualidade e com a socialização do conhecimento.

Palavras-chaves: Curso de Ciências Sociais. Ensino de Sociologia. Núcleo de Ensino. Experiência educacional.
\end{abstract}

\begin{abstract}
The aim of this paper is to develop some reflections about the trajectory of the course of Social Sciences in the Faculty of Philosophy and Science — Unesp/Marília — by means of the historical-cultural theory, and to reveal the most relevant contributions to the formation of the teacher of Sociology, in the context of the implementation of Sociology, as an obligatory discipline, in the senior high school, all over the country, aiming to the formation of a professional aware of the quality of public education and of knowledge socialization.

Key words: Course of Social Sciences. Teaching of Sociology. Nucleus of Teaching. Educational experience.
\end{abstract}

${ }^{1}$ Docente da Faculdade de Filosofia e Ciências - UNESP - Campus de Marília
${ }^{2}$ Docente da Faculdade de Filosofia e Ciências - UNESP - Campus de Marília

MEDIAÇÕES, LONDRINA, V. 12, N. 1, P. 159-176, JAN/JUN. 2007

- 159 


\section{INTRODUÇÃO}

Sociologia no currículo da escola brasileira lhe dá um status de disciplina A conjuntural, que alterna períodos de presença e ausência, determinados por 1 contextos históricos específicos. Neste sentido, a formação de professores de Sociologia para o ensino médio expressa esse diferenciador: a própria trajetória da disciplina na grade curricular dessa modalidade de ensino. Isso não se verifica, da mesma forma, nas disciplinas já consolidadas na escola.

Essa problemática começa a ser mais investigada por pesquisadores da área, como um elemento importante na própria formação dos professores de Sociologia, uma vez, que se não houver maior compreensão desse fenômeno, este se torna um primeiro e não desprezível obstáculo à continuidade da licenciatura do curso de Ciências Sociais (CS). A formação de profissionais de nível superior para um mercado de trabalho, no mínimo, restrito e muitas vezes inexistente, causa a compulsoriedade da certificação, entendida como 0 impedimento real do exercício da profissão, já que não há concurso para disciplina de Sociologia devido a sua ausência no currículo (BARBOSA; MENDONÇA, 2003)³.

Essas questões são preocupações de um conjunto de professores da licenciatura de CS da Faculdade de Filosofia e Ciências da Unesp, campus de Marília, que têm buscado, ao longo da história do curso, um caminho próprio para enfrentar essa difícil situação. Assim, nosso objetivo neste artigo éfazer um balanço dessa trajetória, sob a perspectiva da teoria histórico-cultural, e destacar as contribuições mais interessantes à formaç̧ão do professor de Sociologia, que seja expressão de um profissional comprometido com a educação pública de qualidade e com a socialização do conhecimento, atributos tão ausentes na realidade atual.

\section{A Licenciatura na Unesp/Marília}

\section{BREVE HISTÓRICO}

0 curso de CS foi instituído em 03/03/1963, sendo reconhecido oficialmente, a partir de 11/11/1963. Inicialmente funcionava apenas no período diurno, e a partir de 1971 também no período noturno. A trajetória do Curso de CS apresenta-se complexa, na medida em que implementou distintos projetos e propostas pedagógicas, pois buscava identificar um perfil do cientista social em consonância com um projeto pedagógicocientífico, que garantisse a integração entre o ensino e a pesquisa. Tal fato fortaleceria as CS para uma atuação e adequação às conjunturas de mudança, levando também em consideração a regulamentação da profissão de sociólogo em território nacional.

\footnotetext{
${ }^{3}$ Artigo resultante da pesquisa junto a egressos do curso de CS, realizada em 1998/99, pelo Núcleo de Ensino.
} 
A reforma na universidade brasileira, imposta a partir de 1968, com base nas novas diretrizes delineadas pelo governo militar, obrigou mudanças significativas no curso de Ciências Sociais que passou a oferecer: Licenciatura e Bacharelado em CS e Licenciatura em Estudos Sociais. A demanda por professores, particularmente quando houve a junção de História e Geografia, criando a disciplina de Estudos Sociais no currículo da educação básica, explica a obrigatoriedade da formação em Estudos Sociais e de duas licenciaturas. Cabe ressaltar que houve uma intervenção de cunho ideológico.

As várias mudanças curriculares do curso, ao longo da história, possibilitaram retomar a formação específica em CS com um fortalecimento do Bacharelado em detrimento da Licenciatura. 0 auge dessa postura ocorreu em 1992, quando a nova estrutura do curso fixou a Licenciatura como um "apêndice" da formação do Bacharelado, ou seja, os alunos só completavam a Licenciatura após o cumprimento das disciplinas obrigatórias do Bacharelado.

Essa opção evidencia a dificuldade do conjunto dos professores em perceber as especificidades de cada perfil profissional e em considerar que, para ser bom professor, basta apenas ser bom pesquisador. Todavia, sabe-se que um bom professor deve ter um bom domínio teórico e desenvolver pesquisas adequadas ao seu fazer pedagógico, onde a dicotomia professor pesquisador não se consubstancie.

Outro aspecto importante dessa mudança se reflete no arrefecimento do mercado de trabalho dos professores de Sociologia no ensino médio. Estamos em tempos de neoliberalismo e cada vez mais a política educacional no estado de São Paulo vai assumir a postura de pragmatismo na resolução dos seus problemas, combinando supostos bons resultados com economia de recursos financeiros.

A última reforma, decorrente da regulamentação de dispositivos da LDB (lei no 9394/96), que instituiu a carga horária de 300h à disciplina Prática de Ensino, foi realizada em 1999. Frente à exigência da legislação, aliada aos resultados de pesquisa com egressos da licenciatura de CS, o curso fez esta alteração curricular, atendendo, em parte, à demanda efetiva de egressos, que, naquele momento, não conseguiam fazer concurso na área de História e Geografia, pois não tinham formação e certificação para isso. Porém, efetivamente, há anos eram professores dessas disciplinas na Rede Pública Estadual. A demanda real, na verdade, era por uma complementação, a ser oferecida pela Unesp, nas áreas de História e Geografia.

Após amplo debate no curso, a solução encontrada foi dividir a carga horária de Prática de Ensino em 3 disciplinas: Prática de Ensino de CS I (Sociologia, 120h), Prática de Ensino de CS II (História, 90h), Prática de Ensino de CS III (Geografia, 90h). Essa foi a solução possível, pois a complementação não se apresentava como a melhor saída para 
o problema, uma vez que se estaria precarizando a formação de professores dessas outras licenciaturas. Além disso, havia a necessidade de se valorizar a formação do professor de Sociologia, o que seria feito por meio de uma carga horária maior da referida disciplina na distribuição das Práticas de Ensino.

Essa nova situação curricular gerou novas demandas e explicitou outras, adormecidas e apontadas pelos egressos: necessidade de articulação entre as disciplinas do curso; maior vínculo entre escola pública e universidade; conhecimento efetivo da realidade da escola. Paulatinamente, com discussões permanentes com os licenciandos de cada ano, configurou-se uma proposta de trabalho que almejava — dentro do curto espaço de um ano da licenciatura — responder aos anseios manifestos, envolvendo um trabalho integrado entre as disciplinas de Prática de Ensino (I, II e III), Didática e Sociologia da Educação $0^{4}$.

Durante o ano de 2001, o curso de CS reuniu-se em um Fórum de avaliação e considerou o projeto da licenciatura ainda incipiente frente à necessidade de fortalecer a presença da Sociologia no ensino médio. 0 resultado dessa discussão foi alterar as disciplinas de Prática de Ensino de História e Geografia, para Prática de Ensino em Antropologia e Ciências Políticas. Considerou-se que o conteúdo da Sociologia no ensino médio deve contemplar a formação teórico/prática das CS (Sociologia, Antropologia e Ciências Políticas). Infelizmente, o resultado dessa discussão não se consubstanciou em mudanças efetivas, prevalecendo as mudanças anteriormente citadas. ${ }^{5}$

\section{Prática Pedagógica e uma nova reflexão teórica}

A difícil tarefa de formar professores, em especial para uma disciplina conjuntural no ensino médio, despertou sempre uma preocupação de um conjunto de docentes que buscou novos caminhos para a compreensão desse fenômeno específico, na perspectiva da teoria histórico-cultural, que pudessem possibilitar uma ação efetiva em tal problemática.

Evidente que tais caminhos se nortearam por uma concepção de educação e licenciatura, que perseguia, em meio à aridez do percurso, um objetivo maior de valorizaçã̃o da própria escola pública e de seus estudantes. Isso implicou pensar a educação na sociedade capitalista no bojo de se suas contradições e entender o processo de exploração

\footnotetext{
${ }^{4}$ As demais disciplinas obrigatórias da licenciatura (Estrutura e Funcionamento de Ensino, Psicologia da Educação, Geografia Social e Geografia da Natureza) ou por falta de professor ou divergência com a proposta, não participaram do trabalho.

5 Em 2006 foi encaminhada uma nova adequação para atender às exigências da Resoluções CNE 1/2001 e 2/2001, que regulamentam as Licenciaturas. Embora tenha sido aprovado pelos órgãos colegiados da Unesp, o curso vem desenvolvendo Fóruns de avaliação e debates na aprovação de uma mudança que efetivamente expresse os anseios de professores e estudantes.
} 
do homem pelo próprio homem, que interfere diretamente em seu processo de humanização. A educação, e em especial a escola, vive hoje contradições que a impedem de cumprir seu papel social central, ou seja, a socialização e a produção de conhecimentos.

Mas serão as contradições geradas no interior do próprio sistema que permitirão rearticular um novo sentido para a educação. Para Marx, a educação é a possibilidade de reconstruir no homem o fazer e o pensar como atividades intrínsecas e inseparáveis da natureza humana. 0 homem, como sujeito social, se diferencia dos outros animais quando interfere na natureza através do trabalho. "Para sobreviver o homem necessita extrair da natureza, ativa e intencionalmente, os meios de sua subsistência. Ao fazer isso ele inicia o processo de transformação da natureza, criando um mundo humano (o mundo da cultura)" (SAVIANI, 1991, p. 19).

Esseé, na verdade, o seu processo de humanização. Nele, o homem, historicamente, apropria-se do mundo da cultura na qual se insere e adquire, por meio dessa apropriação, as características que o fazem essencialmente humano, diferentemente do animal que, para sobreviver em seu meio, necessita adaptar-se a ele, utilizando, para isso, seu aparato biológico.

Em se tratando do ser humano, como afirma Oliveira (2006, p.23),

[...] para viver em sociedade não bastam as bases biológicas que a natureza assegura ao indivíduo geneticamente, mas ele precisa apropriar-se do mínimo daquele patrimônio cultural criado, histórica e socialmente, pelas várias gerações, para poder objetivar-se como ser social, transformando-o pela sua atividade.

Ao longo de seu desenvolvimento filogenético, o homem, por meio de seu trabalho, foi transformando a natureza e se transformando nesse processo. Como afirma Mello (2004, p.137-138),

0 homem, desde o princípio da história humana, não parou de modificar suas condições de vida e a si próprio. Ao mesmo tempo, todo o conhecimento e todos os objetos que foi criando não pararam de ser transmitidos de uma geração para outra, o que possibilitou a história humana. Essa transmissão de uma geração para outra dos conhecimentos, aptidões, habilidades que foram sendo criadas ao longo da história só se tornou possível devido a uma forma de atividade absolutamente própria dos homens: a criação de objetos externos da cultura — os instrumentos de trabalho, as máquinas, a arte. Esses objetos não existiam no início da história humana e se tornaram possíveis pela atividade criadora e produtiva específica do homem: o trabalho.

Existe, então, um conflito constante entre a natureza humana e as relações trabalhistas da sociedade capitalista que vai obrigando o homem a abandonar aquilo 
que o diferencia dos outros animais: a capacidade de refletir sobre suas ações. A educação, então, tem a função de reconstruir em cada ser humano a natureza humana. "Portanto, o que não é garantido pela natureza tem que ser produzido historicamente pelos homens; e aí se incluem os próprios homens" (SAVIANI, 1991, p. 21).

0 homem, entendido como sujeito histórico, constrói a sociedade e ao mesmo tempo se constrói, numa relação constante de autodeterminação e transformação. Neste processo há um conjunto de conhecimento que vai sendo historicamente acumulado e sistematizado. A história só pode ter continuidade a partir do momento em que as novas gerações se apropriam do mundo humano. "0 homem é um ser social não porque ele viva ou goste de viver em grupo, mas porque sem a sociedade, sem os outros com que aprende a ser um ser humano, o homem não se torna humano com inteligência, personalidade e consciência" (MELLO, 2004, p.139). Esta apropriação não ocorre de forma espontânea, é necessário ter instituições e pessoas que intencionalmente desempenhem esta tarefa.

Podemos, pois, dizer que natureza humana não é dada ao homem, mas é por ele produzida sobre a base da natureza bio-física. Conseqüentemente, o trabalho educativo é 0 ato de produzir, direta e intencionalmente, em cada indivíduo singular, a humanidade que é produzida histórica e coletivamente pelo conjunto dos homens. Assim, o objeto da educação diz respeito, de um lado, à identificação dos elementos culturais que precisam ser assimilados pelos indivíduos da espécie humana para que eles se tornem humanos e, de outro lado e concomitantemente, à descoberta das formas mais adequadas para atingir esse objetivo (SAVIANI, 1991, p. 21).

Resultam, daí, algumas reflexões: como essas questões se manifestam num curso de licenciatura de CS e quais suas implicações para a formação do futuro profissional? Qual a intencionalidade dos agentes sociais envolvidos nesse processo?

A análise da trajetória do curso remete-nos a um perfil caracterizado pela fragmentação, que, embora perseguisse a consolidação de um projeto cientificista no bacharelado, não esteve articulado à licenciatura. Há nitidamente dois projetos independentes, que ora estabelecem alguns momentos de diálogo, ora se fecham, um se submetendo sumariamente ao outro. A falta de visão do todo e a fragmentação da formação do bacharel/licenciado de CS colaboram, de modo decisivo, para o processo de formação do futuro professor que, dessa forma, não portará as ferramentas necessárias para o desenvolvimento de seu trabalho pedagógico na perspectiva apontada anteriormente.

Essa constatação mobilizou um conjunto de professores para a construção de um projeto alternativo, na licenciatura, que realmente viesse a interferir nessa realidade. Para tanto, foi de fundamental importância a existência de um programa da Unesp, 
denominado Núcleo de Ensino, caracterizado por um espaço que permitiu o desenvolvimento de pesquisas com egressos do curso, bem como sobre a formação de professores de Sociologia e sua prática pedagógica, desde o final da década de 1980. Nesse tempo, criou-se um acúmulo de conhecimentos dessa problemática, extremamente específica da Sociologia, que foi se consubstanciando em ações junto ao próprio curso, em alguns momentos até em mudanças/adequações curriculares.

Nesse processo, a reflexão da prática pedagógica dos próprios docentes do curso se fez presente, pelo menos para aqueles diretamente envolvidos com o Núcleo de Ensino, à medida que ocorria um questionamento sobre a qualidade do ensino e a adequação dos conteúdos da licenciatura frente ao diagnóstico extremamente desolador da escola pública, resultado das próprias pesquisas realizadas pelo Núcleo de Ensino. Em outras palavras, estávamos nos perguntando: em que medida a própria formação inicial de professores de Sociologia era um elo de questionamento ou de conivência com essa realidade? Quais ferramentas pedagógicas eram trabalhadas com os licenciandos a ponto deles se apropriarem efetivamente delas?

A essência do desenvolvimento cultural do ser humano encontra-se, segundo Vigotski ${ }^{6}$, "na colisão dos desenvolvimentos das formas culturais da conduta, que a criança vai conhecendo, com as formas primitivas que caracterizam seu próprio comportamento" (VYGOTSKI, 1995, p. 142.) Em outras palavras, esse desenvolvimento resulta "de um choque real entre o organismo e o meio, o resultado da ativa adaptação ao meio." (p.143).

Nesse processo de desenvolvimento, as crianças assimilam as formas sociais da conduta pela via das interações que mantêm com as outras pessoas de seu entorno, transferindo-as a si próprias em um processo de internalização do conteúdo cultural em jogo nessas relações.

[...] o entorno não deve ser considerado uma entidade estática e periférica com relação ao desenvolvimento; mas deve ser vista como cambiável e dinâmico. Temos aqui o entorno, uma situação que influi sobre a criança de um ou outro modo e dirige seu desenvolvimento. Mas a criança, seu desenvolvimento, se mantém cambiante e se torna diferente. E não é tão-somente a criança que muda; pois também muda a relaçã̃o entre ela e eu entorno, e o mesmo entorno começa agora a ter uma influência diferente sobre a criança. [...]

[...] Por conseguinte, o que isto significa é que o entorno é um fator no campo do desenvolvimento da personalidade e de seus traços humanos específicos, e seu papel

\footnotetext{
${ }^{6}$ Vigostski é um dos fundadores da teoria histórico-cultural, que também tem em Luria e Leontiev outros importantes representantes.
} 
consiste em servir de fonte deste desenvolvimento, ou seja, o entorno é a fonte do desenvolvimento e não seu âmbito. (VYGOTSKY, 1935, p. 15 e 20. Tradução livre do original.)

Nas relações entre os seres humanos, tem papel fundamental a linguagem: é por meio dos signos que se estabelece a comunicação entre as pessoas. No processo educativo, isso tem uma relevância muito grande, pois as diferentes formas de comunicação verbal entre adultos e crianças transformam-se posteriormente em funções psíquicas:

Podemos formular a lei genética geral do desenvolvimento cultural do seguinte modo: toda função no desenvolvimento cultural da criança aparece em cena duas vezes, em dois planos; primeiro no plano social e depois no psicológico, ao princípio entre os homens como categoria interpsíquica e logo no interior da criança como categoria intrapsíquica. [...] Por trás de todas as funções superiores e suas relações se encontram geneticamente as relações sociais, as autênticas relações humanas (VYGOTSKI, 1995, p. 150).

A partir de Vigotski, e avançando na compreensão do processo desencadeado na infância, mas em continuidade no desenvolvimento humano, professores ligados ao Núcleo de Ensino foram paulatinamente transformando sua própria prática pedagógica, à luz desses valiosos pressupostos teóricos, considerando a multiplicidade de experiências como valorização do entorno para os licenciandos de CS. A concepção de Vigotski sobre entorno leva em conta não só o ambiente, mas a relação de cada indivíduo com esse ambiente, a partir de suas experiências pessoais com o próprio entorno. 0 desenvolvimento de cada indivíduo deve expressar as diferentes relações que cada um foi capaz de estabelecer com o meio social, construindo, assim, um universo rico de novas possibilidades e conhecimentos. Ainda com Vigotski, apreende-se que a vivência é a unidade básica entre o desenvolvimento da personalidade do indivíduo e o meio social em que está inserido.

[...] a vivência da criança é aquela simples unidade sobre a qual é difícil dizer que representa a influência do meio sobre a criança ou uma peculiaridade da própria criança. A vivência constitui a unidade da personalidade e do entorno tal como figura no desenvolvimento. Portanto, no desenvolvimento, a unidade dos elementos pessoais e ambientais se realiza em una série de diversas experiências educacionais da criança. A vivência deve ser entendida como a relação interior da criança como ser humano, com um ou outro momento da realidade. Toda vivência é uma vivência de algo. No há experiências educacionais sem motivo, como não há ato consciente que não fosse ato de consciência de algo. (VYGOTSKI, 1996, p.383. Tradução livre do original.) 


\section{AS NOVAS EXPERIÊNCIAS EDUCACIONAIS NA FORMAÇÃO DE PROFESSORES}

A organização das experiências educacionais se refletiu nas disciplinas de Prática de Ensino de CS (I, II e III), depois envolvendo outras disciplinas (Didática e Sociologia da Educação). A carga horária de aulas teóricas das disciplinas de Prática de Ensino, pela lei, é de 75h, ficando 225h para estágio e outras atividades. Como é impensável um estágio com tal carga horária, destinou-se um total de 50h para estágio presencial nas escolas e as demais, isto é, 175h para as diferentes experiências educacionais que fazem interfaces com Didática e Sociologia da Educação. A riqueza das experiências educacionais écompartilhada entre estudantes e professores (universidade e escolas públicas) e pode ser assim resumida:

Curso de extensão e Ciclo de Debates voltados à formação do professor de Sociologia, envolvendo diferentes docentes de diversas áreas e departamentos da Faculdade (Educação Especial, Políticas Educacionais, Sociologia, Antropologia, Didática, etc.);

Produção de material didático-pedagógico e organização da regência. Este momento é muito importante na formação pedagógica do aluno, pois, a partir de pesquisa já realizada por ele sobre temas relacionados às Ciências Sociais, se faz uma pesquisa didático-pedagógica, visando a transformar esse material inicial em projetos temáticos a serem desenvolvidos nos ensinos fundamental e médio. Para tanto, é apresentado ao aluno um roteiro inicial que 0 orienta nesse processo, com algumas indicações centrais no trabalho: definição do tema e do público a que se destina; justificativa, relacionando o tema com as Propostas Curriculares da CENP, Parâmetros Curriculares e, mais recentemente, Orientações Curriculares Nacionais, na área de Ciências Humanas; elaboração de atividades pedagógicas necessárias ao pleno desenvolvimento da temática; metodologia; elaboração de, no mínimo, um texto didático e sistematização das diferentes fontes pesquisadas (livros, músicas, poesias, pinturas, programas de TV/mídia, etc.). Desse modo, a regência passa a ser um momento do processo de elaboração do material didático-pedagógico. Esse processo inicia-se no $1^{\circ}$ semestre do ano letivo eéfinalizado ao término do $2^{\circ}$ semestre, no fechamento do estágio na escola.

Seminários de temas centrais da escola, que têm se mostrado muito interessantes por serem desenvolvidos ao redor de dois eixos principais "Indisciplina, violência e cidadania na escola: possibilidades de superação?" e "Ciências Sociais na escola: o desafio pedagógico". 
Essas temáticas são abordadas com base em documentos oficiais e bibliografia atualizada, permitindo ao aluno o contato com discussões prioritárias da escola, à luz de diferentes perspectivas teóricas, problematizadas partir da observação que ele faz da escola através do estágio.

Análise sociológica da escola, que acontece quando o aluno/sociólogo é chamado a se manifestar no interior do curso de licenciatura. Essa idéia nasceu da avaliação conjunta de alunos e professores de uma determinada turma, que visava a ajustar melhor o tempo e as atividades para formação do professor de Sociologia. Um dos principais obstáculos enfrentados no início do último ano, destinado à licenciatura, é romper as barreiras e o pré-conceito referentes à educação, especialmente em ser professor da educação básica, expressão de um ranço sistemático de um significativo setor das Ciências Sociais para com essa área. Somente após determinado tempo de leituras, discussões e experiências educacionais, é que o trabalho de sensibilização junto ao futuro professor começa a surtir resultados. Uma das possíveis causas, além do pré-conceito, éa natureza do curso de formação: um curso extremamente teórico, que leva o aluno a encontrar dificuldades para ler o real percebido no dia-a-dia da sociedade. Para enfrentar tal situação, a sugestão foi antecipar a Prática de Ensino de CS I (Sociologia) para o $1^{\circ}$ semestre, a fim de propiciar ao aluno o contato com a realidade da escola básica logo no início, através de uma análise sociológica dessa instituição. Apesar de ainda não devidamente familiarizado com a problemática, no nível mínimo de exigência, o aluno começa a ver sentido e estabelecer significados entre o que lê e discute em aula e o que observa na escola. Esse exercício tornou-se um dos pilares do curso, sendo para a grande maioria dos licenciandos a primeira oportunidade de estabelecer a relação entre teoria e prática. 0 desafio de realizar, mesmo que inicialmente, a análise sociológica, a partir da referência e curiosidade investigativa de cada olhar, motiva imensamente os licenciandos, despertando-os para o exercício profissional em dois âmbitos até então não cogitados, de sociólogos e professores de Sociologia. Evidentes são as dificuldades em empreitar uma atividade pouco explorada pelo curso como um todo, mas o desafio faz com que esses jovens as superem, através de um processo articulador entre teoria e prática. Os resultados são extremamente positivos, ocasionando, inclusive, a transformação da análise sociológica em trabalhos de conclusão de curso (monografias) e artigos de iniciação científica. 
Seminário de Estágio é o espaço reservado ao encontro de pessoas em três momentos diferençados de sua formação como professores de Sociologia: os licenciandos (formação inicial), os licenciados (egressos do curso em exercício da docência na educação básica) e os docentes da licenciatura de CS (pesquisadores e responsáveis pela formação inicial e, em algumas oportunidades, continuada dos professores de Sociologia da educação básica). Esse encontro se reveste da problemática da prática pedagógica e da busca de elaboração de novas ferramentas teórico-culturais, que possam embasar de modo efetivo o trabalho do professor de Sociologia. Essa discussão épermeada por questões extremamente interessantes e polêmicas como a necessidade de sociólogo na escola, o perfil do conteúdo da Sociologia no Ensino Médio, bem como a resistência à Sociologia na escola.

Elaboração do relatório final. Nesse espaço, o licenciando fará a síntese de todo o processo, apresentando uma reflexão sobre o conjunto do curso — das aulas, estágio, atividades diversas, enfim, as novas experiências educacionais —, atuando como sujeito de seu processo de formação para o exercício da docência, a partir de sua experiência concreta na licenciatura.

Projetos do Núcleo de Ensino na área de Ciências Sociais. A realização de projetos de CS, via Núcleo de Ensino, foi essencial para a licenciatura, pois oportunizou bolsas de estudos e recursos às pesquisas na área de CS na escola, através de pesquisa-ação junto às escolas públicas da região de Marília. Essas pesquisas permitiram uma reflexão sistemática: da realidade escolar; da crise de identidade de seus agentes sociais e também da própria instituição escolar; das dificuldades de sala de aula; dos processos de implantação dos Parâmetros Curriculares Nacionais; bem como o estreitamento de relações entre a Universidade e escola pública. 0 principal resultado é a constituição de um processo permanente de produção de conhecimentos nessa área pouca explorada das CS.

Esse processo, além de tratar objetivamente de um projeto de formação de professor de Sociologia, também tem como objetivo a construção de um Laboratório Pedagógico de Ciências Sociais, voltado à educação básica. 0 trabalho articulado entre licenciatura e Núcleo de Ensino vem permitindo a pesquisa mais direcionada na área de metodologia de ensino, que tem na produção do material didático-pedagógico seu elemento norteador. 


\section{A Contribuição do Núcleo de Ensino À LICENCIATURA DE CS}

A experiência da licenciatura de CS/FFC foi conquistada a partir de um trabalho contínuo de alguns professores, que a tomaram como uma de suas prioridades de investigação, correspondendo, portanto, às demandas, constituídas ao longo do tempo, que se efetivaram em caminhos para a reflexão organizada do curso. Um desses espaços se concretizou no Núcleo de Ensino (NE), uma importante experiência da Unesp iniciada em 1987, constituída em programa na área educacional, que visa à construção de uma nova relação entre universidade e a educação básica, através de projetos e assessorias permanentes, em nível local e/ou regional).

Através de atuação sistemática com os níveis antecessores de ensino (pré-escola ao ensino médio), passando pela formação e qualificação dos profissionais da Rede de Ensino, ações pedagógicas junto aos alunos, contemplando, também, a realização de pesquisas educacionais, docentes e alunos da UNESP, juntamente com docentes e especialistas da Rede Pública de Ensino, trabalham coletivamente em projetos. Tal trabalho tem como base fundamental a articulação das atividades de ensino/pesquisa/extensão.

As atividades diferenciadas do NE propiciam, aos alunos participantes, vivenciar problemas do cotidiano escolar de uma forma muito concreta, despertando a sua sensibilidade para a importância da práxis na resolução dos problemas educacionais. Esse fato gerou uma mudança de postura dos alunos, ao terem a possibilidade de superar a fragmentação dos conhecimentos abordados na licenciatura. 0 trabalho sistemático do NE, também com a pesquisa, motivou-os muito na elaboração de bons relatórios, possibilitando a sua divulgação em eventos científicos. A convivência permanente com a Rede Pública de Ensino, mesmo através de um projeto localizado em uma escola, foi disseminando entre eles outros elementos para uma leitura diferenciada da realidade escolar, dando um significado novo às teorias estudadas.

Outra consequiência desse processo foi o despertar do interesse dos alunos e também dos professores para a importância do próprio curso, levando-os a uma reflexão mais profunda sobre os objetivos e estrutura dos mesmos. Em alguns casos, proporcionou atéa reformulação curricular, tanto nos aspectos da reestruturação do currículo, como nos conteúdos das disciplinas, no que tange à formação do professor.

Nesse sentido, a experiência do NE foi um dos fatores fundamentais para que se vislumbrasse uma nova forma de fazer a licenciatura. As atividades implementadas pelo NE funcionaram como um elo integrador entre a sala de aula e a realidade, entre a teoria e a prática, entre o aluno/professor/Rede Pública de Ensino, entre a pesquisa e a ação, universidade e escola. Essa integração possibilitou a superação da dicotomia entre os 
diversos saberes e práticas educacionais, de algum modo, abordados na graduação. Os estágios deixaram de ser, para os alunos, uma observação angustiante e/ou burocrática, para se tornarem um centro de interesse, investigação e ação direcionado ao futuro profissional da educação.

A bem da verdade, énecessário que se diga que a experiência com o NE de Marília não é única; diferentes NE foram se estruturando nos diversos campi da Unesp, abrindo reais perspectivas para, de um lado, requalificar a relação entre universidade e escola pública, em nível infantil, fundamental e médio e, de outro, trabalhar com a formação de professores em todas as áreas do conhecimento. As licenciaturas da Faculdade de Filosofia e Ciências da Unesp, campus de Marilia, se inseriram, desde o início, no trabalho do NE local. Entre elas, a licenciatura do curso de Ciências Sociais.

Apesar de não desfrutar do mesmo espaço na grade curricular que outras disciplinas da educação básica, o trabalho sistemático do NE, na área de CS, na escola ensino fundamental e médio, por meio da realização de diferentes projetos desde 1998 até hoje, e intercalou experiências de $1^{\mathrm{a}} \mathrm{a} 4^{\mathrm{a}}$ séries, em projetos interdisciplinares, com pesquisas feitas junto a egressos do curso; trabalho com professores na escola; análise de políticas educacionais e opção pela sociologia no ensino médio; produção e aplicação de materiais didático-pedagógicos na área de Ciências Sociais, voltados a esses níveis de ensino.

Desde o primeiro projeto, expresso na pesquisa pioneira de CHAMMÉ e MOTT $(1996)^{7}$, na região de Marília, buscou identificar a realidade do ensino da Sociologia nas escolas de $2^{\circ}$ grau (atual ensino médio). Analisando o período de 1984 a 1993, os pesquisadores, embora constatando a quase duplicação de escolas do ensino básico com a referida disciplina, encontraram, também, condições desfavoráveis à consolidação da Sociologia na grade curricular. As razões que explicam tal fato são diversas e indicam desde a falta de condições estruturais até a resistência ideológica de parte significativa da comunidade escolar frente à Sociologia.

A realidade do ensino de Sociologia para $02^{\circ}$ grau revela-se, pois, delicada e preocupante se considerarmos que a pulverização da carga horária, em várias disciplinas distintas, representa a possibilidade que os professores das disciplinas da área de Humanas têm de complementar suas cargas horárias e, então, poderem perceber os parcos rendimentos que o Governo do Estado oferece aos professores da Rede. Com salários aviltados, que mal lhes permite a assinatura de um único jornal que seja, o que dizer sobre a compra de livros? Além disso, estando eles responsáveis

\footnotetext{
${ }^{7} 0$ projeto "A realidade do ensino da sociologia no $2^{\circ}$ grau: inovações e continuidades" foi desenvolvido, junto ao Núcleo de Ensino da FFC/Marília, sob a coordenação dos professores Sebastião Jorge Chammé e Yoshiko Tanabe Mott, ambos professores do Departamento de Sociologia e Antropologia, no ano de 1994.
} 
por diferentes disciplinas, múltiplos programas específicos e iguais Propostas Curriculares, mal lhes sobra tempo para correção de trabalhos e provas de seus alunos... (CHAMMÉ; MOTT, 1996, p. 127).

As dificuldades detectadas para a disciplina de Sociologia, como também para os seus professores, são muito próximas, pois ambos, além dos problemas característicos da educação brasileira, encontram um elemento adicional a sua situação específica na Rede Pública de Ensino, qual seja, a desvalorização dessa disciplina e também do seu profissional, conseqüência direta de décadas da sua inconstante presença no currículo da escola. Esse processo de "entra e sai" do currículo permitiu a consolidação da disciplina Sociologia e, conseqüentemente, o reconhecimento e o "status" das outras disciplinas já consolidadas na grade curricular, como Português e Matemática, fazendo dela uma disciplina conjuntural, sem raízes, sempre à mercê de políticas educacionais incoerentes e implacáveis à formação humanística do aluno, por razões que precisam ser mais bem investigadas.

Além disso, a concepção de sociedade e de educação dominante no Brasil contribuiu significativamente para a maior marginalização da Sociologia na escola.

Diante do quadro já desolador de marginalidade em que se encontra a população brasileira em relação ao processo educativo excludente e expulsivo, no qual apenas pequena parcela que se manteve no processo de escolaridade ou que a ele retornou chega a freqüentar o $2^{\circ}$ grau, pudemos observar - no tocante ao desinteresse ou à desinformação sobre os reais objetivos da Sociologia no $2^{\circ}$ grau - a presença de uma situação de tal sorte reprodutivista e não interpretativa, capaz de contribuir para a geração do desinteresse e o conseqüente distanciamento do papel que o Ensino e $2^{\circ}$ grau, por meio das inter-relações estabelecidas a partir da discussão crítica por disciplinas como a sociologia, poderia desempenhar na formação do indivíduo. (CHAMMÉ; MOTT, 1996, p.123-124).

O diagnóstico elaborado pela primeira pesquisa do NE sobre a realidade da disciplina Sociologia na Rede Pública de Ensino só veio ase agravar, como também toda a problemática da escola. Tivemos, objetivamente, um decréscimo das aulas de Sociologia ${ }^{8}$ nas escolas e 0 surgimento e consolidação de um novo fenômeno: indisciplina e violência na escola.

\footnotetext{
${ }^{8}$ No estado de São Paulo, a Secretaria Estadual de Educação, em recentes medidas de aumento da carga horária no ensino médio, apresentou à Rede Pública a opção por várias disciplinas, entre elas Sociologia e Filosofia. A vencedora foi Filosofia e tal fato acarretou, pelo menos na cidade de Marília, a diminuição da presença da Sociologia, mas esta questão ainda precisa ser mais bem investigada. Em 2006, Conselho Estadual de Educação, através da Indicação nº. 62/06, não torna obrigatória a presença da Sociologia em 2007 nas escolas paulistas. Essas medidas dificultaram a implantação da Resolução CNE nº 04/06, que institui a obrigatoriedade da Sociologia e Filosofia; no caso em questão, as dificuldades são da Sociologia.
} 
Sabemos que a escola expressa, em muito, em seu micro espaço social, os problemas maiores da sociedade. Se há o aprofundamento do nível de exclusão social manifesto pelo desemprego, fome, falta de perspectiva de futuro, etc., também encontraremos na escola não só reflexos desses fenômenos. A própria instituição desencadeia o seu processo de exclusão interno ao discriminar seus agentes sociais frente à ausência de respostas aos problemas que enfrenta no seu dia-a-dia. Nesse contexto que a contribuição das CS ganha uma outra dimensão, como já demonstrava Antonio Candido, em 1955.

Os elementos que integram a vida escolar são em parte transpostos de fora, em parte redefinidos na passagem, para ajustar-se às condições grupais; em parte desenvolvidos internamente e devidos a estas condições. Longe de serem um reflexo da vida da comunidade, as escolas têm uma atividade criadora própria, que faz de cada uma delas um grupo diferente dos demais. (CANDID0, 1983, p. 12-13).

Nos últimos anos, o NE tem sido muito procurado pelas escolas públicas de Marília e região exatamente para assessorá-las na busca de soluções para dois problemas centrais: as dificuldades de aprendizagem dos alunos e a indisciplina. Esses problemas estão presentes desde as escolas das séries iniciais do ensino fundamental até o ensino médio, transformando-se em sério desafio para aqueles que atuam na educação. Neste sentido, alunos e docentes do curso de CS assumiram esse desafio e se envolveram, via NE, nessa nova frente de atuação: a escola em espaço e tempo reais.

Assim, para os graduandos do curso de Ciências Sociais a experiência concreta com educação, através do NE, tem permitido uma formação diferenciada para a docência, mudando sua perspectiva como futuro profissional. 0 trabalho apresentado dá pistas concretas de como a área de Ciências Humanas pode estar contribuindo efetivamente para mudar esse quadro caótico da educação pública. A estratégia de atividades que privilegiem o processo de resgate de identidade dos alunos como sujeito histórico, como aluno, como cidadão dentro do mundo contemporâneo, se mostrou extremamente eficaz. Em decorrência, se apresentou uma demanda efetiva de elaboração de material didáticopedagógico voltado à situação específica de cada trabalho a ser realizado nas classes das escolas do ensino básico. Esses desafios devem se constituir em eixos permanentes na formação de professores na área de Ciências Humanas, em especial, de Sociologia.

Vale lembrar que, desde 2002, a licenciatura de Ciências Sociais trabalha a produção de material didático-pedagógico para o ensino fundamental e médio, abordando temáticas como: a questão racial na escola; cidadania; história do Brasil contada a partir da participação da juventude nos movimentos sociais; questão indígena, questão ambiental; questão do trabalho, do tempo e participação política; história do Brasil a partir de charges de época; etc. Toda a produção foi incorporada ao acervo do NE, que busca 
constituir um Laboratório de Ciências Humanas, construído a partir de experiências significativas na formação dos alunos.

\section{Considerações Finais}

No momento atual, o curso passa por uma nova fase de discussão devido à necessidade de definição da estrutura curricular para a licenciatura. Docentes que participaram dessas experiências educacionais almejam que o conjunto do curso apreenda a riqueza do trabalho gestado na licenciatura.

Muito importante nesse processo foi a grande contribuição que o enfoque da teoria histórico-cultural forneceu na releitura de antigas práticas sempre recorrentes de mesmos equívocos como a dicotomia de bacharelado/licenciatura, teoria/prática, universidade/escola, formação fragmentada, estágio tradicional, entre outros. A teoria permitiu a necessária instrumentalização para a análise do social como determinante do processo de desenvolvimento humano, abordando dialeticamente a influência do entorno (meio social) em cada individualidade e o mesmo meio, entorno, sendo modificado pelas individualidades presentes no processo, considerando, ainda, o conjunto dessas interações influenciando o entorno e cada uma das individualidades. Tal fato implica a intencionalidade dos agentes sociais envolvidos nas interações, isto é, o estabelecimento de uma rede de novos sentidos e significados que venham a desencadear novos processos de apropriação da realidadee, conseqüentemente, a produção e socialização de novos conhecimentos.

Esse caminho se apresenta muito promissor para a formação do professor de Sociologia, que possui uma ferramenta diferenciada das demais licenciaturas exatamente pela natureza do conteúdo teórico e do objeto de estudo das CS, ou seja, a sociedade. Cabe, agora, ganhar novos aliados e direcionar suas intencionalidades.

Assim, as reflexões de Freitas sobre a "qualidade negociada" na escola pública, quando conclui como fundamental a participação de todos os profissionais envolvidos no processo educativo para haver mudanças substanciais na prática pedagógica que aí se pretende desenvolver são mais do que nunca pertinentes. Não se pode negligenciar

[...] [0] fato de que um problema, do ponto de vista dialético, não pode ser resolvido de fora dele, mas sim desde dentro dele, levando em conta as contradições reais da sua existência. Portanto, são os atores sociais envolvidos com os problemas os que detêm conhecimentos importantes sobre a natureza desses problemas, seus limites e possibilidades. (FREITAS, 2002, p. 307). 


\section{REFERÊNCIAS}

BARBOSA, M.V.; MENDONÇA, S.G.L. Licenciatura em ciências sociais: problemas e perspectivas. In: MORTATTI, M.R.L. (Org.). Formação de professores: propostas para ação reflexiva no ensino fundamental e médio. Araraquara: JM Editora, 2003.

CANDIDO, A. Tendências no desenvolvimento da sociologia da educação. In: FORACCHI, M. M.; PEREIRA, L. (Org.). Educação e sociedade: leituras de sociologia da educação. São Paulo: Ed. Nacional, 1983.

CHAMMÉ, S. J.; MOTT, Y. T. A realidade do ensino de sociologia no $2^{\circ}$ grau: inovações e continuidades. In: BICUDO, M. A V.; BERNARD0, M. V. C. (Org.). Núcleos de ensino: um projeto de educação continuada. São Paulo: Ed. Unesp, 1996.

FREITAS, L.C. A internalização da exclusão. Educação e sociedade, Campinas, v. 23, n. 80, p. 301-328, set/2002.

MELLO, S. A. A escola de Vygotsky. In: CARRARA, K. (Org.). Introdução à psicologia. São Paulo: Avericamp. 2004.

MENDONÇA, S.GL.; MILLER, S. (Org.). Vigotski e a escola atual: fundamentos teóricos e implicações pedagógicas. Araraquara: Junqueira \& Marin, 2006.

OLIVEIRA, B. A. Fundamentos filosóficos marxistas da obra vigotskiana: a questão da categoria de atividade e algumas implicações para o trabalho educativo. In: MENDONÇA E MILLER (Org.). Vigotski e a escola atual: fundamentos teóricos e implicações pedagógicas. Araraquara: Junqueira \& Marin, 2006. p.3-26.

SAVIANI, D. Pedagogia bistórico-crítica: primeiras aproximações. São Paulo: Cortez e Autores Associados, 1991.

VYGOTSKI, L.S. Obras escogidas. Tradução: Lydia Kuper.vol.III. Madrid: Visor, 1995. Obras escogidas. Madrid: Visor, 1996. v. 4.

VYGOTSKY, L.S. El problema del entorno. 1935.Mimeo. 